\title{
Association of Apgar Score With Meconium Staining of Amniotic Fluid in Labor
}

\author{
Mehar Masood $^{1}$, Nadia Shahid ${ }^{1}$, Zakia Bano ${ }^{2}$, Fiza Ali Khan ${ }^{3}$, Syeda Fariha Hussain ${ }^{4}$, Hafiza Uroosa ${ }^{5}$, \\ Muzainah Khan ${ }^{6}$, Adnan Anwar ${ }^{7}$, Atif A. Hashmi ${ }^{8}$ \\ 1. Obstetrics and Gynecology, Sindh Government Hospital, Karachi, PAK 2. Obstetrics and Gynecology, Liaquat College \\ of Medicine and Dentistry, Dar-Ul-Sehat Hospital, Karachi, PAK 3. Obstetrics and Gynecology, Dow University of \\ Health Sciences, Civil Hospital, Karachi, PAK 4. Obstetrics and Gynecology, Jinnah Medical and Dental College, \\ Karachi, PAK 5. Medical Affairs, Aspin Pharma, Karachi, PAK 6. Obstetrics and Gynecology, Karachi Medical and Dental \\ College, Karachi, PAK 7. Physiology, Al-Tibri Medical College, Isra University, Karachi, PAK 8. Pathology, Liaquat \\ National Hospital and Medical College, Karachi, PAK
}

Corresponding author: Atif A. Hashmi, atifhashmi345@gmail.com

\section{Abstract}

\section{Objective}

This study aimed to determine the association of Apgar score with meconium staining of amniotic fluid in labor.

\section{Methodology}

A retrospective observational study was carried out through the non-probability convenient sampling technique at the Department of Obstetrics and Gynecology for a duration of six months. Only those women were selected who had more than 24 weeks of gestation period. The women were excluded on the basis of risk factors for fetal distress and breech in late labor.

\section{Results}

A total of 216 pregnant women were selected from the labor room in this study. The mean age of the women was $26.57 \pm 4.28$ years. The gestational age of the women was $36.09 \pm 4.11$ weeks. Moreover, the mean parity of pregnant women was $1.68 \pm 2.53$. It has been observed that the women who had meconium staining, the neonates of 144 (77.4\%) women showed the Apgar score of less than six at one minute. However, for the women without meconium staining, the neonates of only 15(50\%) women showed the Apgar score of less than six at the one-minute interval with a significant association $(\mathrm{p}=0.02)$. With respect to age groups, a significant association of meconium staining with Apgar score was noted in the 21-30 years age group, whereas, no significant association was seen in other age groups. Similarly, a significant association of meconium staining and Apgar score was noted in primiparous women, whereas, no significant association was noted in multiparous women. No significant association of Apgar score and meconium staining was seen with respect to the mode of delivery.

Review began 01/13/2021 Review ended 01/14/2021 Published 01/16/2021

๑) Copyright 2021 Masood et al. This is an open access article distributed under the terms of the Creative Commons Attribution License CC-BY 4.0., which permits unrestricted use, distribution, and reproduction in any medium, provided the original author and source are credited.

\section{Conclusion}

The study has found a relation between the Apgar score and meconium staining of amniotic fluid and reported that the Apgar score of less than six at one minute was significantly associated with meconium staining of amniotic fluid.

Categories: Obstetrics/Gynecology

Keywords: meconium staining, amniotic fluid, apgar score, parity

\section{Introduction}

The amniotic fluid is basically a yellow color fluid that is clear and found in the first 12 days after the female has conceived and is produced inside the amniotic sac. This fluid surrounds the baby, which is growing in the uterus and has major functions to perform, which leads to the healthy development of a fetus. The amount of amniotic fluid that is present inside the uterus is less but has a greater impact on the fetus. It acts as a protective system for both the mother and baby. Initially, the amniotic fluid consists of water which is obtained from the mother's body afterward converted into the baby's urine. Furthermore, there are some nutrients and important hormones along with anti-bodies that protect the fetus from bumps and injuries. Hence, if the level of amniotic fluid is monitored at a very low or high level it can be harmful to both mother and baby [1]. This part that is also known as the post-conception period has been critically advised to be taken extra care of both mother and child since the uterus is quite weak and the next immediate implantation may cause weak immunity, severe headaches followed by nausea, flatulence, cramps, and severe boating. Many women have experienced this condition in the initial trimester. One of the most pertaining factors that are usual during the implantation phase that may be experienced by the women is 
major mood swings and pressure on their lower abdomen. Meconium is a dark green substance that is composed of epithelial cells that are intestinal and contains mucus [2]. Meconium is produced in the fetal gut which is in small quantities as early as the tenth week of pregnancy approaches but, it is not excreted until about the 34th week of pregnancy [3]. It is also suggested that meconium is also secreted in response to fetal hypoxia or reduced clearance due to impaired swallowing or placental dysfunctions. Consequently, this had been used in labor to monitor the fluid which was separated from the womb. Meconium-stained amniotic fluid (MSAF) that occurs during delivery has long been known to be the indicator of adverse fetal and maternal effects such as meconium aspiration and perinatal asphyxia, contributing to perinatal and neonatal morbidity and mortality [4]. Meconium is a dense and black-green odorous substance first recognized during the gestation of the fetal intestine for approximately 12 weeks and deposited in the fetal colon [5].

The passage of meconium in newborns is an incident planned for development usually in the first 24 to $48 \mathrm{~h}$ after birth [6]. However, during pregnancy, the fetus can transfer meconium through the amniotic fluid for various reasons [7]. MSAF is rare before 37 weeks of gestation and increases with increasing gestational age [8]. The occurrence of MSAF during labor can cause adverse outcomes in the fetus, for instance, meconium aspiration syndrome (MAS) and perinatal asphyxia $[9,10]$.

Meconium-stained liquor (MSL) is the passage of meconium in the antenatal or labor cycle by a fetus in utero [11]. In the intrapartum treatment guideline, meconium-stained amniotic fluid is graded as an important MSL and non-important MSL, according to the Royal College of Obstetricians and Gynecologists (RCOG) [12]. Non-important MSL is classified as a thin yellow or greenish tinged fluid; it contains nonparticular meconium, while significant MSL is defined as a dense and stubborn, dark green or black amniotic fluid consisting of the meconium bumps [13].

Apgar score is a rapid method by which fetal well-being is evaluated against infant mortality. It is assessed based on five criteria (skin color, pulse rate, reflex, muscle tone, and respiratory effort) each with a scale of zero to two. Total score range from zero to 10. This study aimed to determine the association of Apgar score with meconium staining of amniotic fluid in labor.

\section{Materials And Methods}

A retrospective observational study was carried out through the non-probability convenient sampling technique at the Department of Obstetrics and Gynecology for a duration of six months. Women with labor pains that had three uterine contractions in $10 \mathrm{~min}$, each lasting more than 30 seconds, with more than 24 weeks of the gestation period and established labor with spontaneous or artificial rupture of membranes were included in the study. However, the women were excluded on the basis of risk factors for fetal distress such as hypertension, diabetes mellitus, or previous cesarean section. Moreover, the women with heavy bleeding per vagina after 28 weeks of gestation (antepartum hemorrhage) along with the breach in late labor, i.e., baby presenting with buttocks or feet, and women with multiple pregnancies, i.e., more than one baby in utero were also excluded from the study. Women were categorized into age groups of $<20$ years, $21-$ 30 years, and 30-40 years. The parity and mode of delivery were recorded.

The data were entered and analyzed on Statistical Package for Social Sciences (SPSS) Statistics version 26.0 (IBM Inc., Armonk, NY). Frequency and percentage were computed for categorical variables like the mode of delivery, parity, booking status, meconium-stained liquor and Apgar score less than six at one minute. Mean and standard deviation were computed for age, parity, and gestational age. For stratification, a crosstabulation technique was used to control effect modifiers such as age groups, parity, and mode of delivery to observe the effect of an outcome. The chi-square test was used to find a proportional difference in Apgar score of less than 6 at one minute with meconium staining. P-values of $\leqslant 0.05$ were considered statistically significant.

\section{Results}

The mean age of the women was $26.57 \pm 4.28$ years. The mean gestational age of the women was $36.09 \pm 4.11$ weeks. Moreover, the mean parity of the pregnant women was $1.68 \pm 2.53$ as shown in Table 1 . 


\section{Cureus}

\begin{tabular}{|lr|}
\hline Variable & Mean \pm SD \\
\hline Age (Years) & $26.57 \pm 4.28$ \\
\hline Parity & $1.68 \pm 2.53$ \\
\hline Gestation Age (Weeks) & $36.09 \pm 4.11$
\end{tabular}

\section{TABLE 1: Descriptive characteristics of women under study}

SD: standard deviation

It has been observed that the women who had meconium staining, the neonates of 144(77.4\%) women showed the Apgar score of less than six at one minute. However, the women who did not have meconium staining, the neonates of only 15(50\%) women showed Apgar score of less than six at the one-minute interval with a significant association $(\mathrm{p}=0.02)$ as shown in Table 2.

\begin{tabular}{|c|c|c|c|}
\hline \multirow{2}{*}{ Meconium staining ( $\mathrm{n}=\mathbf{2 1 6})$} & \multicolumn{2}{|c|}{ Apgar score $<6$ at one minute } & \multirow{2}{*}{ P-value } \\
\hline & Yes & No & \\
\hline Present & 144(77.4\%) & $42(22.6 \%)$ & \multirow{3}{*}{0.002} \\
\hline Absent & $15(50 \%)$ & $15(50 \%)$ & \\
\hline Total & 159 & 57 & \\
\hline
\end{tabular}

TABLE 2: Association of Apgar score of less than six at one minute with meconium staining

With respect to age groups, the significant association of meconium staining with Apgar score was noted in the 21-30 years age group, whereas, no significant association was seen in other age groups. Similarly, the significant association of meconium staining and Apgar score was noted in primiparous women, whereas, no significant association was noted in multiparous women. No significant association of Apgar score and meconium staining was seen with respect to the mode of delivery (Table 3). 


\begin{tabular}{|c|c|c|c|c|c|}
\hline \multirow{2}{*}{ Variables } & & \multirow{2}{*}{ Meconium staining } & \multicolumn{2}{|c|}{ Apgar score $<6$ at one minute } & \multirow{2}{*}{ P-value } \\
\hline & & & Yes & No & \\
\hline \multirow{5}{*}{ Age groups (years) } & $<20$ & Absent & $0(0.0 \%)$ & $1(100.0 \%)$ & 0.16 \\
\hline & \multirow{2}{*}{21 to 30} & Present & $114(77.6 \%)$ & $33(22.4 \%)$ & \multirow{2}{*}{0.011} \\
\hline & & Absent & $14(53.8 \%)$ & $12(46.2 \%)$ & \\
\hline & \multirow{2}{*}{31 to 40} & Present & $10(62.5 \%)$ & $6(37.5 \%)$ & \multirow{2}{*}{0.54} \\
\hline & & Absent & $1(33.3 \%)$ & $2(66.7 \%)$ & \\
\hline \multirow{4}{*}{ Parity } & \multirow{2}{*}{ Primipara } & Present & $67(81.7 \%)$ & $15(18.3 \%)$ & \multirow{2}{*}{0.004} \\
\hline & & Absent & $6(42.9 \%)$ & $8(57.1 \%)$ & \\
\hline & \multirow{2}{*}{ Multipara } & Present & $77(74.0 \%)$ & $27(26.0 \%)$ & \multirow{2}{*}{0.149} \\
\hline & & Absent & $9(56.2 \%)$ & $7(43.8 \%)$ & \\
\hline \multirow{4}{*}{ Mode of delivery } & \multirow{2}{*}{ Emergency cesarean section } & Present & $115(82.1 \%)$ & $25(17.9 \%)$ & \multirow{2}{*}{0.22} \\
\hline & & Absent & $7(63.6 \%)$ & $4(36.4 \%)$ & \\
\hline & \multirow{2}{*}{ Spontaneous vaginal delivery } & Present & $29(63.0 \%)$ & $17(37.0 \%)$ & 0.12 \\
\hline & & & & & \\
\hline
\end{tabular}

TABLE 3: Association of Apgar score and meconium staining with respect to different variables

\section{Discussion}

In this study, we found a significant association of meconium staining of amniotic fluid with Apgar score, thus signifying the predictive value of meconium-stained amniotic fluid for fetal wellness. The increased incidence of meconium-stained amniotic fluid with advancing gestational age probably reflects the maturation of peristalsis in the fetal intestine. It has been observed that meconium-stained infants are usually born with clear amniotic fluid. A study by Duhan et al. for the period of three months to evaluate the presence of meconium at the onset of labor and its obstetric outcome, reported that out of the 1267 deliveries, $7.89 \%$ had meconium staining of liquor. In comparison with our study, the sample was much smaller with 216 cases and a high prevalence of meconium-stained amniotic fluid seen in 86.11\% (186/216). The above study also reported adverse outcomes such as fetal heart rate abnormalities in women with meconium staining. Moreover, thick meconium staining was found in women with the higher cesarean section along with a low Apgar score at the one-minute interval. However, the frequency of Apgar score of less than six at one minute was reported to be elevated in meconium-stained and primiparous women. Moreover, both studies showed a strong relationship between meconium staining of amniotic fluid and Apgar score at the one-minute interval [14].

The age of women is also related to the development of MSAF. The study conducted in 2006 reported that women with more than 30 years of age were 5.6 times more susceptible to develop MSAF during labor than those less than 30 years. This is due to the fact that in older age, aging of uterine blood vessels and arterial stiffness results in insufficient placental perfusion leading toward the passage of meconium in the amniotic fluid [15]. On contrary, the other study found that women between 20 and 30 age groups had a high rate of Apgar score at one minute. Moreover, these women were also found with the presence of meconium-stained amniotic fluid [16].

Another study by Steer and colleagues revealed a relationship between meconium staining of the amniotic fluid and Apgar score. The sample size was larger $(\mathrm{n}=1219)$ compared to our study $(\mathrm{n}=216)$. The results revealed the presence of acidosis in the fetus whose mothers have MSAF during labor [17]. Alternatively, Grignaffini and colleagues found that in cases with MSAF, adverse fetal outcomes were absent with an Apgar score of less than seven at five minutes [18].

Another study reported that $48.8 \%$ of MSAF born babies had a low Apgar score of less than seven at one minute [19]. Similarly, the study by Bochner et al. reported that $40.3 \%$ of babies among the MSAF group had a low Apgar score at one minute compared to 3.9\% in clear liquor babies [20]. Similarly, in our study, we found that the frequency of Apgar score of less than 6 at one minute was significantly higher in meconium- 
stained women.

Swain and Thapalial in 2008 predicted different associated syndromes in MSAF women. They further found significant risk factors associated with MAS, which include increased gestational age, increased cesarean section (LSCS), and low Apgar scores at 1 and $5 \mathrm{~min}$ [21]. On the contrary, a cross-sectional study conducted in 2004-2005 found no relation between MAS and type of delivery, and gestational age [22].

There were a few limitations to the study. First, a retrospective study design leads to the introduction of several confounding factors that cannot be controlled. Second, other sequel of meconium staining on fetal well being and other associated risk factors were not evaluated. Moreover, the sample size of the study was relatively small.

\section{Conclusions}

We found a significant association of Apgar score at one minute with meconium staining of amniotic fluid. Moreover, after stratification of age, parity, and mode of delivery, we noted that the association of Apgar score and meconium staining of amniotic fluid was only significant in age groups between 21 and 30 years and primiparous women. More prospective studies are required to further explore the effects of meconium staining on neonates and the reasons for the low Apgar score.

\section{Additional Information \\ Disclosures}

Human subjects: Consent was obtained or waived by all participants in this study. Animal subjects: All authors have confirmed that this study did not involve animal subjects or tissue. Conflicts of interest: In compliance with the ICMJE uniform disclosure form, all authors declare the following: Payment/services info: All authors have declared that no financial support was received from any organization for the submitted work. Financial relationships: All authors have declared that they have no financial relationships at present or within the previous three years with any organizations that might have an interest in the submitted work. Other relationships: All authors have declared that there are no other relationships or activities that could appear to have influenced the submitted work.

\section{References}

1. Ziadeh SM, Sunna E: Obstetric and perinatal outcome of pregnancies with term labour and meconiumstained amniotic fluid. Arch Gynecol Obstet. 2000, 264:84-87. 10.1007/s004040000088

2. Lee KA, Lee SM, Yang HJ, Park CW, Mazaki-Tovi S, Yoon BH, Romero R: The frequency of meconiumstained amniotic fluid increases as a function of the duration of labor. J Matern Fetal Neonatal Med. 2011, 24:880-885. 10.3109/14767058.2010.531329

3. Alchalabi HA, Obeidat BR, Jallad MF, Khader YS: Induction of labor and perinatal outcome: the impact of the amniotic fluid index. Eur J Obstet Gynecol Reprod Biol. 2006, 129:124-127. 10.1016/j.ejogrb.2005.10.039

4. Crowley P, O'Herlihy C, Boylan P: The value of ultrasound measurement of amniotic fluid volume in the management of prolonged pregnancies. Br J Obstet Gynaecol. 1984, 91:444-448. 10.1111/j.14710528.1984.tb04781.x

5. Oyelese Y, Culin A, Ananth CV, Kaminsky LM, Vintzileos A, Smulian JC: Meconium-stained amniotic fluid across gestation and neonatal acid-base status. Obstet Gynecol. 2006, 108:345-349. 10.1097/01.AOG.0000226853.85609.8d

6. Greenwood C, Lalchandani S, MacQuillan K, Sheil O, Murphy J, Impey L: Meconium passed in labor: how reassuring is clear amniotic fluid?. Obstet Gynecol. 2003, 102:89-93. 10.1016/s0029-7844(03)00407-1

7. Scott H, Walker M, Gruslin A: Significance of meconium-stained amniotic fluid in the preterm population . J Perinatol. 2001, 21:174-177. 10.1038/sj.jp.7200521

8. Rathor AM, Singh R, Ramji S, Tripathi R: Randomised trial of amnioinfusion during labour with meconium stained amniotic fluid. BJOG. 2002, 109:17-20. 10.1111/j.1471-0528.2002.01140.x

9. Meis PJ, Hall M 3rd, Marshall JR, Hobel CJ: Meconium passage: a new classification for risk assessment during labor. Am J Obstet Gynecol. 1978, 131:509-513. 10.1016/0002-9378(78)90111-4

10. Hiersch L, Krispin E, Aviram A, Wiznitzer A, Yogev Y, Ashwal E: Effect of meconium-stained amniotic fluid on perinatal complications in low-risk pregnancies at term. Am J Perinatol. 2016, 33:378-384. 10.1055/s0035-1565989

11. Gregory GA, Gooding CA, Phibbs RH, Tooley WH: Meconium aspiration in infants--a prospective study . J Pediatr. 1974, 85:848-852. 10.1016/s0022-3476(74)80358-6

12. Hiersch L, Melamed N, Rosen H, Peled Y, Wiznitzer A, Yogev Y: New onset of meconium during labor versus primary meconium-stained amniotic fluid - is there a difference in pregnancy outcome?. J Matern Fetal Neonatal Med. 2014, 27:1361-1367. 10.3109/14767058.2013.858320

13. Monen L, Hasaart TH, Kuppens SM: The aetiology of meconium-stained amniotic fluid: pathologic hypoxia or physiologic foetal ripening? (Review). Early Hum Dev. 2014, 90:325-328. 10.1016/i.earlhumdev.2014.04.003

14. Duhan N, Paul A, Duhan U, Anjali: Meconium staining of amniotic fluid- a poor indicator of fetal compromise. JK Sci. 2010, 12:184-186.

15. David AN, Njokanma OF, Iroha E: Incidence of and factors associated with meconium staining of the amniotic fluid in a Nigerian University Teaching Hospital. J Obstet Gynaecol. 2006, 26:518-520. 10.1080/01443610600797426 


\section{Cureus}

16. Puertas A, Paz Carrillo M, Moltó L, Alvarez M, Sedeño S, Miranda JA: Meconium-stained amniotic fluid in labor: a randomized trial of prophylactic amniofusion. Eur J Obstet Gynecol Reprod Biol. 2001, 99:33-37. 10.1016/s0301-2115(01)00354-2

17. Steer PJ, Eigbe F, Lissauer TJ, Beard RW: Interrelationships among abnormal cardiotocograms in labor, meconium staining of the amniotic fluid, arterial cord blood pH, and Apgar scores. Obstet Gynecol. 1989, 74:715-721.

18. Osava RH, Silva FM, Vasconcellos de Oliveira SM, Tuesta EF, Amaral MC: Meconium-stained amniotic fluid and maternal and neonatal factors associated. [Article in Portuguese]. Rev Saude Publica. 2012, 46:10231029. 10.1590/s0034-89102013005000005

19. Tairy D, Gluck O, Tal O, et al.: Amniotic fluid transitioning from clear to meconium stained during laborprevalence and association with adverse maternal and neonatal outcomes. J Perinatol. 2019, 39:1349-1355. 10.1038/s41372-019-0436-4

20. Bochner CJ, Medearis AL, Ross MG, Oakes GK, Jones P, Hobel CJ, Wade ME: The role of antepartum testing in the management of postterm pregnancies with heavy meconium in early labor. Obstet Gynecol. 1987, 69:903-907.

21. Swain P, Thapelial A: Meconium stained amniotic fluid - a potential predictor of meconium aspiration syndrome. J Nepal Paediatr Soc. 2008, 28:3-9. 10.3126/jnps.v28i1.1397

22. Chinese Collaborative Study Group for Neonatal Respiratory Diseases: Treatment of severe meconium aspiration syndrome with porcine surfactant: a multicentre, randomized, controlled trial. Acta Paediatr. 2005, 94:896-902. 10.1111/j.1651-2227.2005.tb02008.x 